\title{
Immunological Detection of a Novel Advanced Glycation End-Product
}

\author{
Masayoshi Takeuchi, ${ }^{1}$ Yukiko Yanase, ${ }^{1}$ Nobuyasu Matsuura, ${ }^{2}$ Sho-ichi Yamagishi, ${ }^{3}$ Yukihiko \\ Kameda, ${ }^{1}$ Richard Bucala, ${ }^{4}$ and Zenji Makita ${ }^{3}$ \\ ${ }^{1}$ Department of Biochemistry, Faculty of Pharmaceutical Science, Hokuriku University, Kanazawa, Japan \\ ${ }^{2}$ Biotechnology Research Center, Toyama Prefectural University, Toyama, Japan \\ ${ }^{3}$ Division of Endocrinology and Metabolism, Department of Medicine, Kurume University School of \\ Medicine, Kurume, Japan \\ ${ }^{4}$ The Picower Institute for Medical Research, Manhasset, New York, U.S.A.
}

Contributed by R. Bucala. Accepted September 24, 2001

\begin{abstract}
Background: The advanced stage of the Maillard reaction that leads to the formation of advanced glycation endproducts (AGEs) plays an important role in the pathogenesis of angiopathy in diabetic patients and in the aging process. Recently, it has been proposed that the intermediates contributing to AGE formation include dicarbonyl intermediates such as glyoxal, methylglyoxal, and 3-deoxyglucosone (3-DG). In the present study, we developed a novel, non-carboxymethyllysine (CML) anti-AGE antibody that recognizes serum proteins and peptides modified by 3-DG in vivo.

Materials and Methods: AGE-modified serum albumins were prepared by incubation of rabbit serum albumin with 3-DG or D-glucose. After immunization of rabbits, anti-AGE antisera were subjected to affinity chromatography on a Sepharose $4 \mathrm{~B}$ column coupled with CML-BSA, or AGE-BSA created by incubation with 3-DG (AGE-6) or
\end{abstract}

D-glucose (AGE-1). The AGE-Ab-6 and AGE-Ab-1 thus obtained was used to investigate AGEs in serum from diabetic patients on hemodialysis.

Results: Characterization of the novel AGE-Ab-6 obtained by immunoaffinity chromatography was performed with a competitive ELISA and immunoblot analysis. This antibody specifically cross-reacted with proteins modified by 3-DG. AGE-6 was detected in diabetic serum as three peaks with apparent molecular weights of 200, 1.15, and $0.85 \mathrm{kD}$, while AGE-1 was detected as four peaks with apparent molecular weights of 200, 65, 1.15, and $0.85 \mathrm{kD}$.

Conclusion: This study provides new data on the pathways of AGE formation from 3-DG and methods for the immunochemical detection of AGEs. We also provide immunochemical evidence for the existence of six distinct AGEs in vivo among the AGE-modified proteins and peptides in the serum of diabetic patients on hemodialysis.

\section{Introduction}

The modification, aggregation, and deposition of proteins is a prominent part of many pathological processes and can play a direct role in tissue damage. The pathological role of the nonenzymatic modification of proteins by glucose, a process which is known as glycation, has become increasingly evident in different diseases. It is now well established that early glycation products undergo progressive modification over time in vivo with the formation of irreversible cross-links, forming moieties termed advanced glycation end-products (AGEs). AGEs have been implicated in the development of many of the pathological sequelae of diabetes and aging, such as atherosclerosis and renal insufficiency (1-4). Recently, it has become clear that AGEs also have a role in neurodegenerative diseases such as Alzheimer's

Send correspondence and reprint requests to: Masayoshi Takeuchi, Department of Biochemistry, Faculty of Pharmaceutical Science, Hokuriku University, 3-Ho Kanagawa-machi, Kanazawa-city, Ishikawa 920-1181, Japan. Phone: +81-76-229-6197; fax: +81-76-229-2781;

e-mail: m-takeuchi@hokuriku-u.ac.jp. disease (5-8), Parkinson's disease (9), and amyotrophic lateral sclerosis (ALS) $(10,11)$.

AGEs are formed by glycation, which is a nonenzymatic reaction between ketones or aldehydes and the amino groups of various proteins that contributes to the aging of proteins and to the complications of diabetes (1-4). In the presence of hyperglycemia, glucose reacts with the free amino groups of amino acids, proteins, phospholipids, and nucleic acids. This process begins with the conversion of reversible Schiff base adducts to more stable, covalently-bound Amadori rearrangement products. Over the course of several days to weeks, these Amadori products then undergo further rearrangement to form irreversibly-bound AGEs, a process known as the Maillard reaction. In the intermediate stage of the Maillard reaction, the Amadori products undergo multiple dehydration steps and rearrangements that produce highly reactive carbonyl compounds such as 3-deoxyglucosone (3-DG) (12-15). These reactive carbonyl compounds again react with free amino groups, leading to cross-linking and browning of proteins and the formation of AGEs in the late stage of the Maillard reaction (16). However, 
our knowledge about the heterogeneous AGEs formed in vivo is limited and many of these products are still largely undefined at the chemical level (17).

3-DG may be formed non-enzymatically from Amadori compounds or enzymatically by decomposition of fructose-3-phosphate, a product of the fructose-3-phosphokinase reaction (18). 3-DG reacts rapidly with protein amino groups to form various AGEs $(19,20)$, such as pyrraline, pentosidine, carboxymethyllysine (CML), and imidazolones. Studies using gas chromatography-mass spectrometry (GC-MS) (21) or electrospray ionization liquid chromatography mass spectrometry (ESI/LC/MS) (22) have shown that plasma 3-DG levels are markedly increased in patients with diabetes or uremia. Although some of the AGE-modified proteins prepared in the laboratory exhibit a variety of biological activities, the AGEs known to exist in vivo have not yet been demonstrated to show significant biological effects. 3-DG is potent at forming AGEs and has several biological activities (20), such as cytotoxicity, suggesting that it may be important in the development of diabetic and uremic complications.

To better understand the role of 3-DG in the modification of proteins in patients with diabetes, we developed a new antibody to non-CML AGEs that could recognize serum proteins modified by 3-DG. We have now prepared a total of six anti-AGE antibodies in order to better identify compounds involved in the Maillard reaction in vivo. The present study provides direct immunological evidence for the existence of six distinct classes of AGE-modified proteins and peptides (AGE-1 to -6) in the serum of diabetic patients on hemodialysis.

\section{Materials and Methods}

Synthesis of 3-Deoxyglucosone (3-DG)

3-DG was synthesized according to the method of Khadem et al. (23) with some modifications. For the initial synthesis of 3-DG-bisbenzoylhydrazone, a solution of D-glucose (15 g), $p$-toluidine $(8.25 \mathrm{~g})$, and acetic acid $(16.5 \mathrm{ml})$ in $95 \%$ ethanol $(337 \mathrm{ml})$ was boiled under reflux for $30 \mathrm{~min}$ and then benzoylhydrazine $(24.7 \mathrm{~g})$ was added, followed by refluxing for $7 \mathrm{~h}$. The reaction mixture then was let stand at $4^{\circ} \mathrm{C}$ overnight, filtered, washed successively with ethanol and diethyl ether, and dried at room temperature. The residue was recrystallized from $95 \%$ ethanol as a monohydrate, with a yield of $16.5 \mathrm{~g}$ $(50 \%)$. For the synthesis of $3-D G$, a solution of 3-DG-bisbenzoylhydrazone ( $10 \mathrm{~g})$, ethanol $(300 \mathrm{ml})$, $\mathrm{H}_{2} \mathrm{O}(500 \mathrm{ml})$, acetic acid $(22 \mathrm{ml})$, and freshly distilled benzaldehyde was refluxed for $6 \mathrm{~h}$. After $3 \mathrm{~h}$, the ethanol was removed by evaporating $300 \mathrm{ml}$ of the solution with the simultaneous dropwise addition of $500 \mathrm{ml} \mathrm{H}_{2} \mathrm{O}$. After $18 \mathrm{~h}$, the precipitate was removed by filtration, following which the filtrate was concentrated to $40 \mathrm{ml}$ and washed with diethyl ether $(200 \mathrm{ml}, 6$ times). The concentrate then was evaporated to $10 \mathrm{ml}$ and applied to an ion-exchange resin column (Amberlite IR 120B, 100 ml; Amberlite IR 4B, $100 \mathrm{ml}$ ). The eluate was lyophilized, dissolved in a small quantity of methanol, and purified by silica gel flash column chromatography $(4 \times 20 \mathrm{~cm})$ with a chloroform/methanol (7:3) solvent system. Decolorization was performed with activated charcoal. Next, the filtrate containing 3-DG was evaporated to dryness, and then the residue was dissolved in a small amount of water and was lyophilized, yielding $3.0 \mathrm{~g}(73 \%)$. The spectral data for 3-DGbisbenzoylhydrazone, as well as the Rf value and the TLC dye pattern of 3-DG, all corresponded with those reported previously (23). When a solution of purified 3-DG (0.12 g) and benzoylhydrazine $(0.16 \mathrm{~g})$ in water $(10 \mathrm{ml})$ was heated for a few minutes in a boiling water bath according to the method of Khadem et al. (23), the product that separated was 3-DGbisbenzoylhydrazone at a yield of $0.22 \mathrm{~g}(78 \%)$. These data indicated that the compound synthesized was pure 3-DG.

\section{Preparation of AGE-Proteins, CML, and CEL}

AGE-BSA and AGE-rabbit serum albumin (RSA) were prepared as described previously (24-26). Briefly, each protein was incubated under sterile conditions with D-glucose (AGE-1), glyceraldehyde (AGE-2), glycolaldehyde (AGE-3), methylglyoxal (AGE-4), glyoxal (AGE-5), or 3-DG (AGE-6) and $5 \mathrm{mM}$ diethylenetriamine-pentaacetic acid (DTPA) in $0.2 \mathrm{M}$ phosphate buffer $(\mathrm{pH} 7.4)$ at $37^{\circ} \mathrm{C}$ for 7 days, except in the case of incubation with 3-DG (2 weeks) or D-glucose (8 weeks). Low molecular weight reactants and aldehydes were removed using PD-10 column chromatography and dialysis against PBS. Carboxymethyllysine (CML)-BSA was prepared as described elsewhere (27). Briefly, $50 \mathrm{mg} / \mathrm{ml}$ of BSA was incubated at $37^{\circ} \mathrm{C}$ for $24 \mathrm{~h}$ with $45 \mathrm{mM}$ glyoxylic acid and $150 \mathrm{mM}$ sodium cyanoborohydride $\left(\mathrm{NaCNBH}_{3}\right)$ in $2 \mathrm{ml}$ of $0.2 \mathrm{M}$ phosphate buffer (pH 7.4), followed by PD-10 column chromatography and dialysis against PBS. Carboxyethyllysine (CEL)-BSA also was prepared as described elsewhere (28). Briefly, $50 \mathrm{mg} / \mathrm{ml}$ of BSA was incubated at $37^{\circ} \mathrm{C}$ for $24 \mathrm{~h}$ with $45 \mathrm{mM}$ pyruvic acid and $150 \mathrm{mM}$ sodium cyanoborohydride $\left(\mathrm{NaCNBH}_{3}\right)$ in $2 \mathrm{ml}$ of $0.2 \mathrm{M}$ phosphate buffer ( $\mathrm{pH} 7.4$ ), followed by PD-10 column chromatography and dialysis against PBS. Protein concentrations were determined with the Dc protein assay reagent (Bio-Rad Laboratories, Richmond, CA) using BSA as a standard.

\section{Preparation of Polyclonal Anti-AGE Antibodies}

Four milligrams of each of two types AGE-RSA (incubated with 3-DG and D-glucose) were emulsified in $\mathbf{5 0 \%}$ Freund's complete adjuvant and injected intradermally into rabbits. This procedure was repeated at weekly intervals for 6 weeks. After a 2 -week pause, the rabbits were given a booster injection of $4 \mathrm{mg}$ of each antigen. Animals were bled 
on the tenth day after this injection and serum was obtained for purification.

\section{Purification of Antibodies to Non-CML AGE (AGE-Ab-1 and -6) from Polyclonal AGE Antibodies by Affinity Chromatography}

Antibodies specific for non-CML AGE were isolated from the above-mentioned rabbit antiserum by affinity chromatography. AGE-BSA created by incubation with D-glucose (AGE-1) or incubation with 3DG (AGE-6) or CML-BSA (100 mg of each protein) was coupled to $20 \mathrm{ml}$ of CNBr-activated Sepharose $4 \mathrm{~B}$ according to the manufacturer's instructions. Then $25 \mathrm{ml}$ of rabbit serum was applied to a column $(2.5 \times 5.5 \mathrm{~cm})$ of Sepharose 4B coupled with AGE-1 or AGE-6. After extensive washing with PBS, the adsorbed fractions were eluted with $20 \mathrm{mM}$ sodium phosphate buffer containing $1 \mathrm{M}$ potassium thiocyanate ( $\mathrm{pH}$ 7.4). The AGE antibody fractions were pooled, concentrated using Centriprep-10, and passed through a PD-10 column equilibrated with PBS. The AGE antibodies thus obtained were then loaded onto a column $(1.5 \times 5.5 \mathrm{~cm})$ of Sepharose $4 \mathrm{~B}$ coupled with CML-BSA, which was washed with $30 \mathrm{ml}$ of PBS to obtain the unadsorbed fraction (nonCML AGE antibodies). The adsorbed fraction (CML antibody) was then eluted with $20 \mathrm{ml}$ of $20 \mathrm{mM}$ sodium phosphate buffer containing $1 \mathrm{M}$ potassium thiocyanate $(\mathrm{pH} 7.4)$. Fractions $(1.0 \mathrm{ml})$ were monitored for absorbance at $280 \mathrm{~nm}$. The unadsorbed fractions were pooled, concentrated with Centriprep-10, and passed through a PD-10 column equilibrated with PBS for use in this study.

\section{Enzyme-Linked Immunosorbent Assay (ELISA)}

Ligand inhibition and AGE measurements were performed with a competitive ELISA, as described previously (24-26). Briefly, samples $(50 \mu \mathrm{l})$ were added to each well as a competitor for $50 \mu \mathrm{l}$ of nonCML AGE antibodies (1:500-1:2000), followed by incubation for $2 \mathrm{~h}$ at room temperature with gentle shaking on a horizontal rotary shaker. Results were expressed as $\mathrm{B} / \mathrm{B}_{0}$, which was calculated as follows; (experimental OD-background OD)/(total ODbackground OD). The immunoreactivity of each fraction was read from the calibration curve (for AGE-1 or AGE-6) and was expressed as AGE units (U) per $\mathrm{ml}$, with one unit corresponding to the amount of antibody-reactive material found in AGE-BSA at a protein concentration of $1 \mu \mathrm{g} / \mathrm{ml}$.

\section{Size Distribution of Non-CML AGE in Serum from Diabetic} Patients on Hemodialysis

Fifty milliliters of serum from 10 patients with type 2 diabetes and end-stage renal disease on hemodialysis was subjected to ultrafiltration using a PM-10 membrane (cut-off MW $10 \mathrm{kD}$ ) to separate the high molecular weight fraction $(>10 \mathrm{kD})$ from the low molecular weight fraction $(<10 \mathrm{kD})$. The high molecular weight fraction was applied to a Sephacryl S-200 column $(1.5 \times 110 \mathrm{~cm})$, which was equilibrated with PBS (pH 7.4) and eluted with the same buffer (fraction size: $1.5 \mathrm{ml}$, flow rate: $10 \mathrm{ml} / \mathrm{h}$ ) in a cold room. The molecular weight markers used were aldolase (MW 160,000), BSA (MW 67,000), chymotrypsinogen A (MW 25,000), and vitamin $B_{12}$ (MW 1,355). The low molecular weight fraction was pooled, concentrated by lyophilization, and dissolved in a small volume of distilled water. The precipitate was removed by centrifugation at 10,000 rpm for $10 \mathrm{~min}$ and the supernatant was applied to a Sephadex G-15 column $(1.5 \times 110 \mathrm{~cm})$, which was equilibrated with $50 \mathrm{mM}$ ammonium acetate buffer (pH 7.4) and eluted with the same buffer (fraction size: $1.5 \mathrm{ml}$, flow rate: $8 \mathrm{ml} / \mathrm{h}$ ) in a cold room. The molecular weight markers used were cytochrome c (MW 12,500), vitamin $\mathrm{B}_{12}$ (MW 1,355), and cytidine (MW 243). Each fraction was monitored for absorbance at $280 \mathrm{~nm}$ and the AGE activity of each fraction was measured by both AGE-ELISA and characteristic AGE-specific fluorescence (Ex $=360 \mathrm{~nm} /$ $\mathrm{Em}=440 \mathrm{~nm})$. The immunoreactivity of each fraction was read from the calibration curve (for AGE-1 or AGE-6) and was expressed as AGE units (U) per $\mathrm{ml}$, as described above.

\section{Immunoblot Analysis}

AGE-proteins and human serum protein samples were subjected to electrophoresis on $7.5 \%$ SDS gel or $5-20 \%$ gradient SDS gel. The proteins then were transferred electrophoretically to PVDF membranes for $30 \mathrm{~min}$ at $2.5 \mathrm{~mA}$ per $\mathrm{cm}^{2}$. Each membrane was blocked with $4 \%$ skim milk in PBS for $1 \mathrm{~h}$ at room temperature, reacted for $2 \mathrm{~h}$ with immunoaffinitypurified antibodies (1:250-1:1000 diluted in 4\% skim milk in PBS), washed three times for $5 \mathrm{~min}$ each with PBS-Tween 20 buffer, incubated for $1 \mathrm{~h}$ in 4\% skim milk in PBS with 1:2000 diluted antirabbit IgG coupled to alkaline phosphatase, washed 5 times for 5 min each with PBS-Tween 20, and finally incubated with 5-bromo-4-chloro-3-indoyl phosphate-nitroblue tetrazolium.

\section{Results}

\section{Characterization of the Immunogen}

The formation of AGE by rabbit serum albumin (AGE-RSA) during incubation with 3-DG for 2 weeks was monitored by AGE-specific fluorescence. Fluorescence was only associated with the AGE-RSA complex, and was not seen in control RSA after 2 weeks of incubation without 3-DG (data not shown). The excitation and emission maximum of AGE-RSA was 360 and $440 \mathrm{~nm}$, respectively, in close agreement with the values for glucose-modified AGE-RSA $(25,26)$. SDS-PAGE under reducing conditions revealed that unglycated RSA (incubated without 3-DG) migrated at $68 \mathrm{kD}$, while AGE-RSA (incubated with $0.2 \mathrm{M}$ 3-DG for 2 weeks) migrated more slowly and formed 
a broad band around $68 \mathrm{kD}$, suggesting that covalently linked adducts of RSA had been formed nonenzymatically during incubation (data not shown).

\section{Characterization of AGE Antiserum}

We prepared AGE-6 antiserum from rabbits immunized with AGE-RSA (2 weeks of incubation with 3-DG). This antiserum was applied to an affinity column coupled with AGE-BSA (AGE-6) to obtain a purified anti-AGE antibody. Figure 1 shows the cross-reactivity for carboxymethyllysine (CML)BSA, AGE-BSA (AGE-6), and unmodified BSA of the polyclonal antibody obtained from rabbits immunized with AGE-RSA. The antibody reacted with AGE-BSA (AGE-6), whereas no reaction was observed with unmodified BSA (Fig. 1) or with BSA that had been incubated without 3-DG (data not shown). In cross-reactivity studies, this antibody also showed a weak reaction with CML-BSA (Fig. 1). It therefore seemed likely that the polyclonal antiserum not only contained an antibody specific for non-CML AGE (AGE-6), but also an antibody for CML.
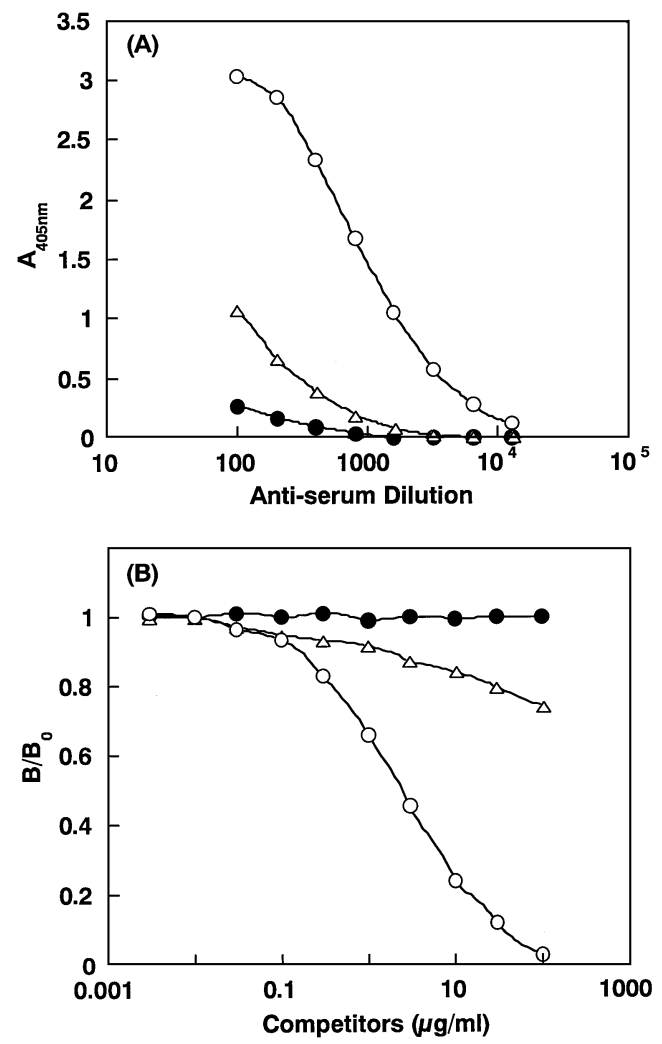

Fig. 1. Immunoreactivity of AGE-6 antiserum. The immunoreactivity of AGE-6 antiserum with AGE-BSA ( $\bigcirc$, AGE-6) CML-BSA $(\triangle)$, and native BSA $(\bullet)$ was determined at various concentrations by competitive ELISA. Details are described in Materials and Methods. (A): non-competitive ELISA employing bound ligand. (B): competitive ELISA employing bound ligand, and AGE-BSA, CML-BSA, or unmodified BSA as competitors.
Separation of non-CML AGE Antibodies from Polyclonal AGE Antibodies

The polyclonal AGE antisera obtained after incubation of AGE-RSA with 3-DG or glucose were purified by AGE-BSA (AGE-6 or AGE-1) affinity chromatography, and then were separated by CML-BSA affinity chromatography (Fig. 2). We calculated the percentage of antibodies bound to the CML affinity gel (eluted as the second peak) relative to that of antibodies unbound to the affinity gel (eluted as the first peak). Unbound AGE-6 antibody (the non-CML AGE fraction) accounted for $83 \%$ (Fig. 2A) of all antibodies obtained. In our previous study $(24,25)$, we used $1 \mathrm{mM}$ EDTA as a chelator when preparing AGE-1, which meant that it may have still contained many CML structures. In this study, therefore, we prepared AGE-1 in the presence of $5 \mathrm{mM}$ diethylenetriamine-pentaacetic acid (DTPA). Antibodies unbound to the CML affinity gel and eluted as the first peak accounted for $67 \%$ of those obtained from rabbits immunized with AGE-RSA after incubation for 8 weeks with $0.5 \mathrm{M}$ glucose in the
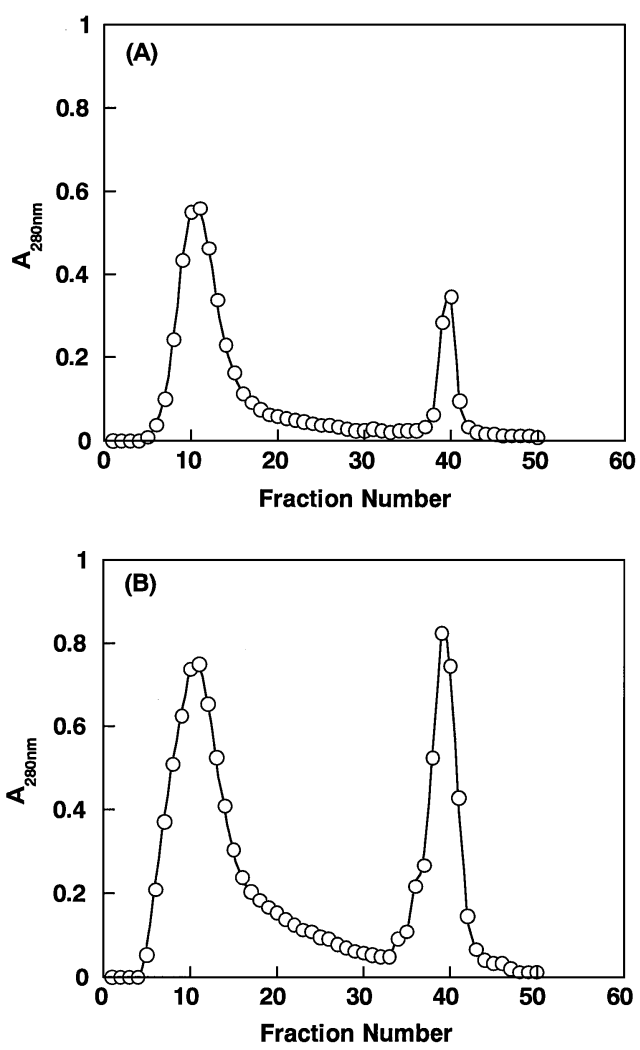

Fig. 2. Separation of non-CML anti-AGE antibodies from polyclonal anti-AGE antibodies by CML-BSA affinity chromatography. Affinity chromatography was performed with polyclonal anti-AGE antisera raised against RSA incubated for 2 weeks with 3 -deoxyglucosone (A), or for 8 weeks with glucose $(\mathbf{B})$. 
presence of DTPA (Fig. 2B) versus $35 \%$ of those obtained using AGE-RSA incubated with EDTA in our previous study (25).

\section{Characterization of Non-CML AGE Antibodies}

Characterization of the non-CML AGE antibodies obtained by CML-BSA affinity chromatography was done using a competitive ELISA with several AGE-modified proteins (Fig. 3). Binding of the two non-CML AGE antibodies (AGE-Ab-1 and -6) to each AGE-BSA was not altered by the addition of glycated HSA (data not shown), indicating that early glycation products such as Amadori products were not the immunoreactive epitopes. We also investigated whether non-CML AGE antibodies purified by CML-BSA affinity chromatography could react with CML-BSA and carboxyethyllysine (CEL)-BSA. Neither CML-BSA or CEL-BSA inhibited the binding of non-CML AGE antibodies to each type of AGE-BSA (data not shown). Pentosidine-BSA, pyrraline-BSA, and argpyrimidine-BSA also did not inhibit the binding of these non-CML AGE antibodies (data not shown). To determine which kinds of AGE were recognized by these non-CML AGE antibodies, BSA was incubated with glucose (AGE-1), glyceraldehyde (AGE-2), glycolaldehyde (AGE-3), methylglyoxal (AGE-4), glyoxal (AGE-5), and 3-DG (AGE-6). As shown in Figs. $3 A \& B, A G E-A b-6$ specifically inhibited the binding of AGE-6 and AGE-Ab-1 specifically inhibited the binding of AGE-1 (Figs. 3CED). Immunoblot analysis with immunoaffinity-purified antibodies confirmed the results obtained by ELISA (data not shown). These findings indicated that AGE-BSA modified by 3-DG had the highest reactivity for AGE-Ab-6.
Size Distribution of AGE in Serum from Diabetic Patients on Hemodialysis

Using the affinity purified non-CML AGE antibodies (AGE-Ab-1 and -6), we examined the size distribution of AGEs in serum from Type 2 diabetic patients on hemodialysis using Sephacryl S-200 column chromatography. Figure $4 \mathrm{~A}$ shows the distribution of the high molecular weight fraction in serum from the diabetic patients detected by monitoring the absorbance at $\mathbf{2 8 0} \mathrm{nm}$ or the AGE-specific fluorescence. Figure 4B shows the distribution detected by each type of non-CML AGE antibody (obtained from rabbits immunized using AGE-RSA incubated with glucose or 3-DG, respectively). AGE1 immunoreactive material was eluted as two peaks with an apparent molecular weight of $200 \mathrm{kD}$ and 65 $\mathrm{kD}$, while AGE-6 immunoreactive material was eluted as one peak with an apparent molecular weight of $200 \mathrm{kD}$. The AGE-1 peak was much higher than that for AGE-6. Immunoblotting of serum protein samples with affinity-purified AGE-Ab-6 revealed major immunoreactivity with an apparent molecular weight of $200 \mathrm{kD}$ (data not shown). Minor immunoreactivity was also observed with some high molecular weight proteins larger than albumin. These findings supported the ELISA results.

We also examined AGE in the low molecular weight fraction of serum from the diabetic patients using Sephadex G-15 column chromatography. Figure 5A shows the distribution of AGE in the low molecular weight fraction determined by monitoring the absorbance at $280 \mathrm{~nm}$ or the AGE-specific fluorescence. Figure 5B shows the results obtained with the affinity purified non-CML AGE antibodies. Non-CML AGE immunoreactive material was eluted as two peaks by the two types of non-CML
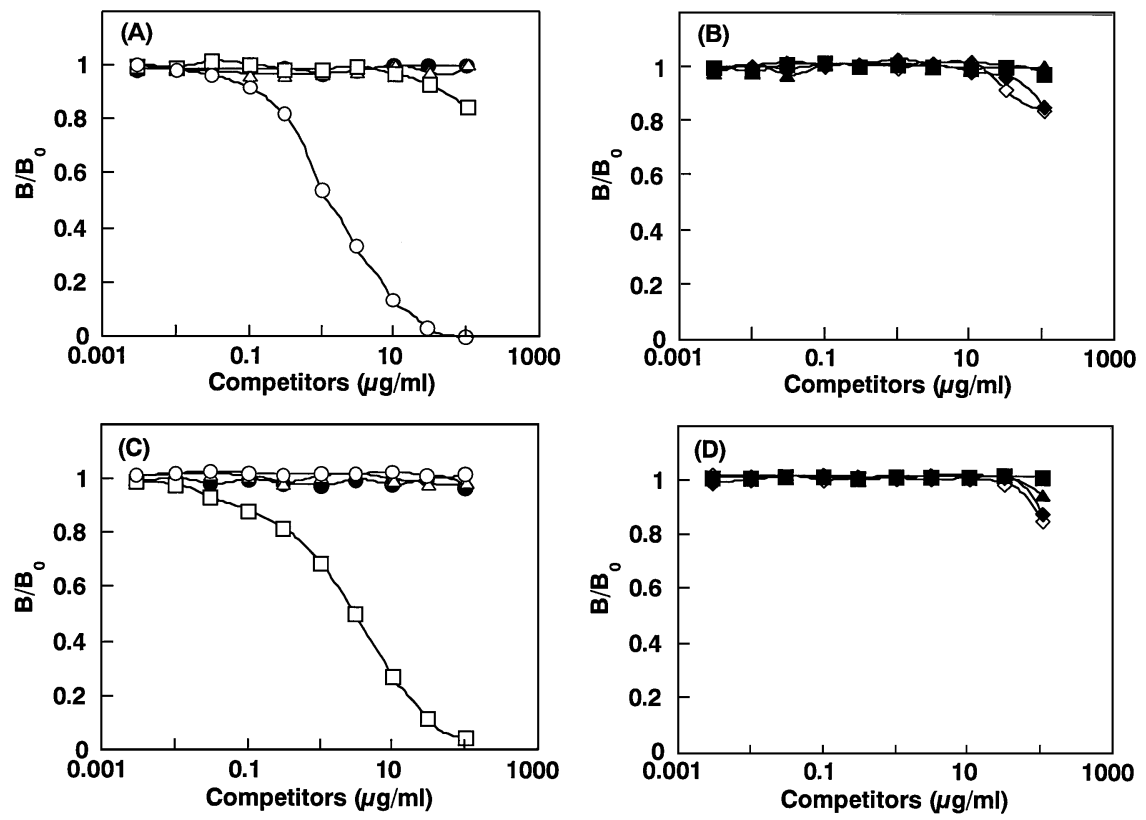

Fig. 3. Immunoreactivity of non-CML anti-AGE antibodies with various AGE preparations. Non-CML anti-AGE antibody was raised against AGE-RSA prepared by incubation with 3-DG $(\mathbf{A}, \mathbf{B})$, and glucose

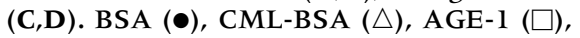
AGE-2 $(\diamond), \operatorname{AGE}-3(\diamond), A G E-4(\square), A G E-5$ $(\Delta)$, and AGE-6 (O). 

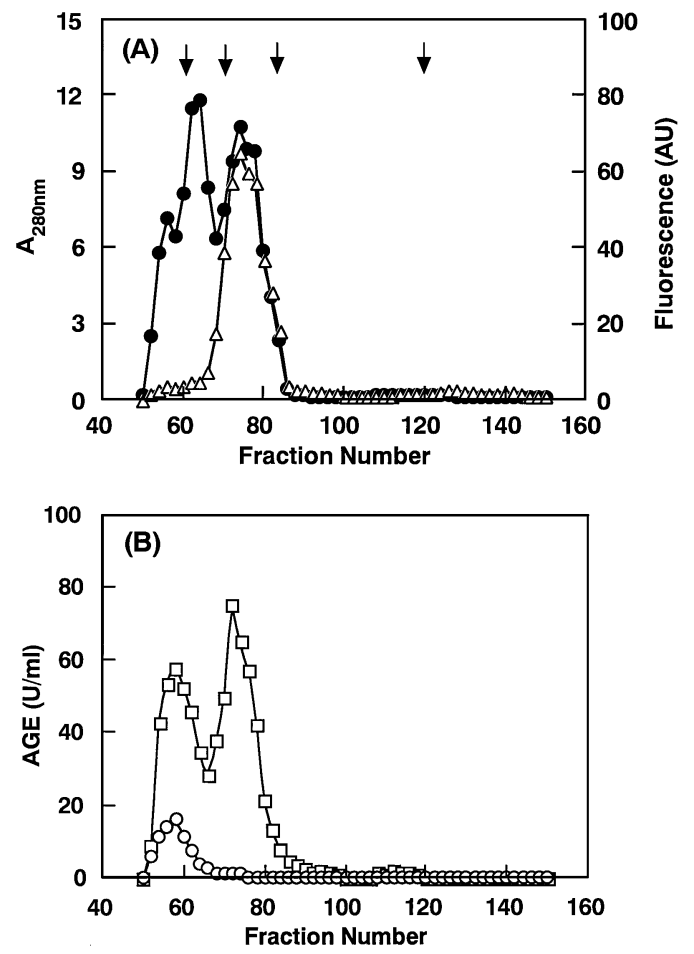

Fig. 4. Size distribution of high molecular weight AGEproteins from diabetic patients on hemodialysis. High molecular weight protein fractions obtained from diabetic patients with end-stage renal disease on hemodialysis were subjected to gel filtration chromatography (Sephacryl S-200 column: $1.5 \times$ $110 \mathrm{~cm})$. The eluted fractions were monitored for non-CML AGE ( $\square$, AGE-1; $\bigcirc$, AGE-6) by ELISA (data from triplicate determinations), AGE fluorescence $(\triangle, \mathrm{Ex}=360 \mathrm{~nm} / \mathrm{Em}=$ $440 \mathrm{~nm})$, and absorbance at $280 \mathrm{~nm}(\bullet)$. Elution of aldolase $(160,000)$, BSA $(67,000)$, chymotrypsinogen A $(25,000)$, and vitamin $B_{12}(1,355)$ (MW-markers) is indicated by arrows.

(A): Chromatography monitored by AGE fluorescence and absorbance at $280 \mathrm{~nm}$. (B): Chromatography with affinity purified non-CML anti-AGE antibodies obtained by incubation of AGERSA with glucose and 3-DG.

AGE antibodies (obtained from rabbits immunized by AGE-RSA incubated with glucose or 3-DG), and these peaks contained species with an apparent molecular weight of $1.15 \mathrm{kD}$ and $0.85 \mathrm{kD}$. There was more immunoreactive AGE-1 than AGE-6 in the low molecular weight fraction.

\section{Discussion}

There is general agreement that there are multiple sources and mechanisms involved in the formation of AGEs in vivo, including oxidative and nonoxidative processing of reducing sugars, Schiff bases, Amadori adducts, and metabolic intermediates such as glyceraldehyde and methylglyoxal (MGO) $(17,25,26,29-36)$. In model systems, AGEs have been shown to arise from the metal-catalyzed autoxidation of glucose, with the dicarbonyl glyoxal (GO) and arabinose as intermediates (37), and from the decomposition of Amadori products to the reactive dicarbonyl 3-deoxyglucosone (3-DG) (38).
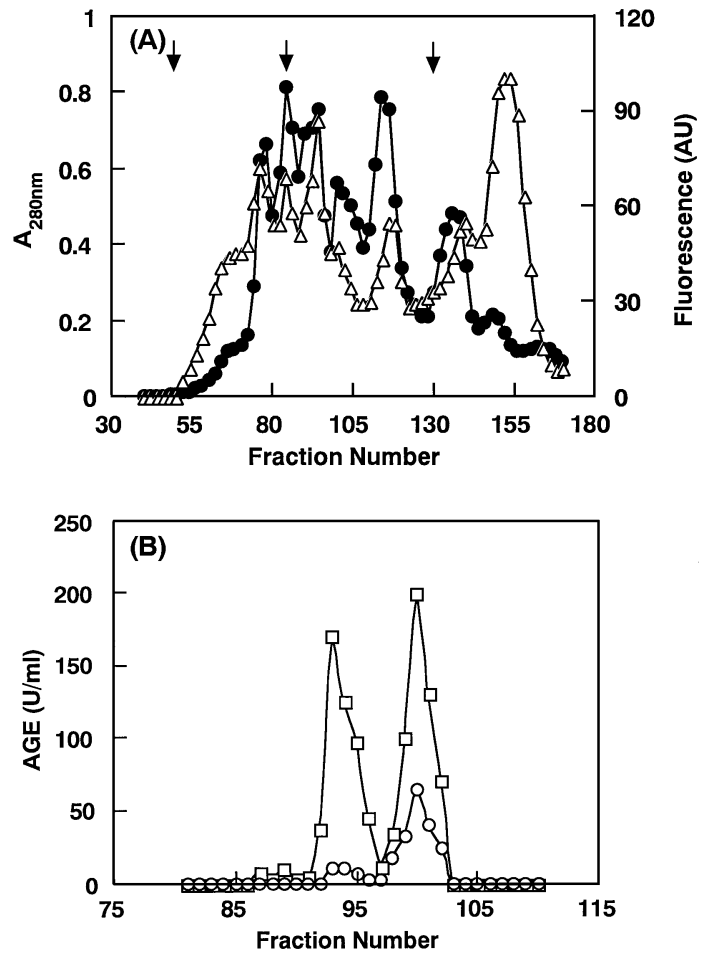

Fig. 5. Size distribution of low molecular weight AGEpeptides from diabetic patients on hemodialysis. Low molecular weight fractions obtained from diabetic patients with end-stage renal disease on hemodialysis were subjected to gel filtration chromatography (Sephadex G-15 column:1.5 $\times$ $110 \mathrm{~cm})$. The eluted fractions were monitored for non-CML AGE( $\square$, AGE-1; $\bigcirc$, AGE-6) by ELISA (data from triplicate determinations), $\mathrm{AGE}$ fluorescence $(\triangle, \mathrm{Ex}=360 \mathrm{~nm} / \mathrm{Em}=$ $440 \mathrm{~nm})$, and absorbance at $280 \mathrm{~nm}(\bullet)$. Elution of cytochrome c $\left(\mathrm{V}_{0}\right)$, vitamin $\mathrm{B}_{12}(1,355)$, and cytidine (243) (MW-makers) is indicated by arrows. (A): Chromatography monitored by AGE fluorescence and absorbance at $280 \mathrm{~nm}$. (B): Chromatography with affinity purified non-CML anti-AGE antibodies raised against AGE-RSA incubated with glucose or 3-DG.

We recently used RSA modified by incubation with glucose (AGE-1), $\alpha$-hydroxyaldehydes (glyceraldehyde (AGE-2) and glycolaldehyde (AGE-3)), or the dicarbonyl compounds (MGO (AGE-4) and GO $(\mathrm{AGE}-5))$ to immunize rabbits and obtain a high titer of antiserum without any reactivity for the carrier proteins $(25,26)$. Using immuno-affinity chromatography, we then produced five specific antibodies for non-CML AGEs that recognized the five immunoreactive types of AGEs (AGE-1, -2, -3, -4 , and -5). In the present study, we developed another antibody to a non-CML AGE (AGE-Ab-6) that recognizes serum proteins modified by 3-DG. AGE-Ab-6 specifically reacted with protein modified by 3-DG (AGE-6), but did not cross-react with proteins modified by glucose (AGE-1), $\alpha$-hydroxyaldehydes (glyceraldehyde (AGE-2) and glycolaldehyde (AGE-3)), or dicarbonyl compounds (MGO (AGE-4) and GO (AGE-5)). The epitope of the AGEAb-6 seems to be different from pentosidine, pyrraline, or argpyrimidine, because BSA preparations 
conjugated with these compounds also were not recognized by this antibody.

In a previous study, we provided direct immunochemical evidence for the existence of at least five distinct AGEs (AGE-1 to -5) among the AGEmodified proteins and peptides that circulate in the serum of diabetic patients on hemodialysis $(25,26)$. The estimated size of the high molecular weight AGE-proteins detected by our AGE-ELISA using a specific antibody (AGE-Ab-1) for glucose-derived non-CML AGE (AGE-1) were $200 \mathrm{kD}$ and $65 \mathrm{kD}$ (Fig. 4B, 25). Antibodies to the other four types of non-CML AGE (AGE-2, -3, -4, and -5) recognized immunoreactive material that was eluted as a single peak with an apparent molecular weight of $200 \mathrm{kD}$ (26). Immunoblotting of serum protein samples with these non-CML AGE antibodies also showed major immunoreactivity with an apparent molecular weight of $200 \mathrm{kD}$ (26). We also examined AGE in the low molecular weight fraction of serum from diabetic patients, and found that immunoreactive material detected by AGE-Ab-1, -2, -4, and -5 eluted as two peaks with apparent molecular weights of 1.15 and $0.85 \mathrm{kD}$, while AGE-Ab-3 detected immunoreactive material that eluted as a single peak with an apparent molecular weight of $0.85 \mathrm{kD}(25,26)$.

In the present study, 3-DG-derived non-CML AGE (AGE-6) was detected among the low molecular weight AGE-peptides and eluted as two peaks with apparent molecular weights of 1.15 and $0.85 \mathrm{kD}$ (Fig. 5). AGE-6 also was detected among the high molecular weight AGE-protein as a peak at $200 \mathrm{kD}$ (Fig. 4). Furthermore, immunoblotting of serum protein samples with AGE-Ab-6 showed major immunoreactivity with an apparent molecular weight of $200 \mathrm{kD}$ (data not shown). Thus, these six non-CML AGE antibodies (AGE-Ab-1 to -6) have enabled us to detect various compounds created by glycation in vivo.

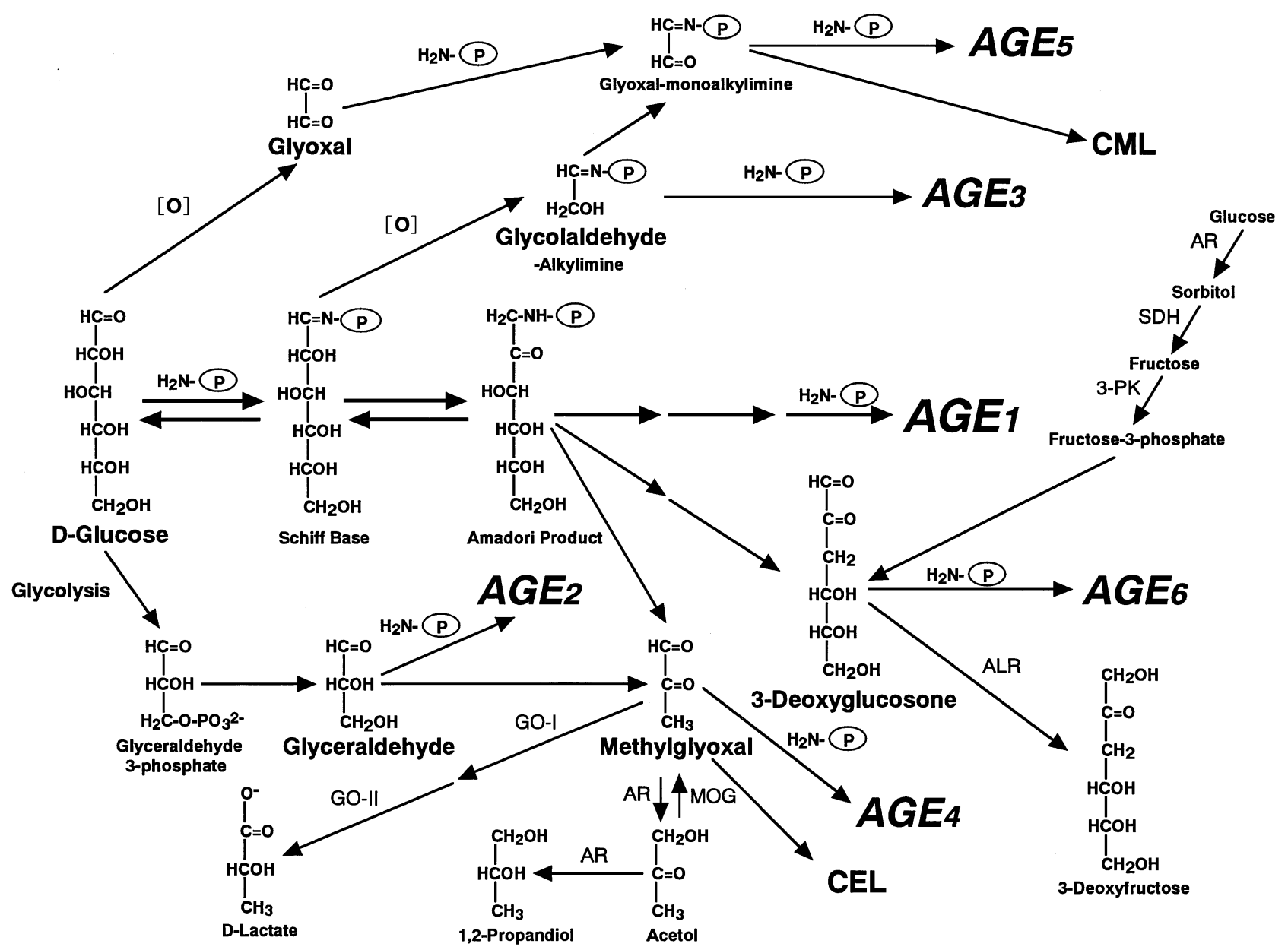

Fig. 6. Alternative routes for the formation of immunochemically distinct AGEs in vivo. Advanced glycation end-products (AGEs) arise from the decomposition of Amadori products (AGE-1), the glycolysis intermediate product glyceraldehyde (AGE-2), the Schiff base fragmentation product glycolaldehyde (AGE-3), the triose phosphate and the Amadori product fragmentation product methylglyoxal (AGE-4), the autoxidation product of glucose glyoxal (AGE-5), and decomposition product of Amadori products and fructose-3-phosphate to 3-DG (AGE-6). CML, N-(carboxymethyl)lysine; CEL, N-(carboxyethyl)lysine; (D)- $\mathrm{NH}_{2}$, free amino residue of protein (AR, aldose reductase; SDH, sorbitol dehydrogenase; 3-PK, fructose-3-phosphokinase; ALR, aldehyde reductase; GO, glyoxalase; MOG, mono-oxygenase). 
We recently reported evidence for the toxicity of a specific AGE, classified as AGE-2, for rat primary cultured cortical neurons (29). In preliminary studies, we have observed cytotoxic activity for AGE-6 as well, but not nearly to the degree as that found for AGE-2, which was more toxic than AGE-1 (data not shown).

In both our previous work $(25,26)$ and in this study, we have provided data on the pathways of AGE formation and methods for the immunochemical detection of AGEs. We also have provided direct immunological evidence for the existence of six distinct AGEs (designated as AGE-1 to -6) among the AGE-modified proteins and peptides in the serum of diabetic patients on hemodialysis. These various types of non-CML AGE (AGEs-1 to -6) appear to be formed by glycation, sugar autoxidation, and sugar metabolism in vivo, as outlined in Fig. 6. Further studies will help to elucidate how such modifications of proteins contribute to the tissue complications of diabetes and the neurodegenerative disease.

\section{Acknowledgments}

These studies were supported in part by a Grantin-Aid for Scientific Research (\#13470197) to Masayoshi Takeuchi from the Japanese Ministry of Education, Science, Sports, and Culture, by a research grant to Masayoshi Takeuchi from Japan Foundation for Aging and Health, by a research grant to Masayoshi Takeuchi from the Hokuriku University, by a research foundation (\#12HIAC124) to Masayoshi Takeuchi from the Hokuriku Industrial Advancement Center, and by the diabetes research foundation (\#1-2000-263) to Soroku Yagihashi from Juvenile Diabetes Foundation International.

\section{References}

1. Bucala R, Cerami A. (1992) Advanced glycosylation: chemistry, biology, and implications for diabetes and aging. $A d v$. Pharmcol. 23: 1-34.

2. Vlassara H, Bucala R, Striker L. (1994) Pathogenic effects of AGEs: biochemical, biologic, and clinical implications for diabetes and aging. Lab. Invest. 70: 138-151.

3. Brownlee M. (1995) Advanced protein glycosylation in diabetes and aging. Ann. Rev. Med. 46: 223-234.

4. Vlassara H. (1997) Recent progress in advanced glycation end products and diabetic complications. Diabetes 46: S19-S25.

5. Vitek MP, Bhattacharya K, Glendening JM, et al. (1994) Advanced glycation end products contribute to amyloidosis in Alzheimer disease. Proc. Natl. Acad. Sci. USA 91: 4766-4770.

6. Smith MA, Taneda S, Richey PL, et al. (1994) Advanced Maillard reaction end products are associated with Alzheimer disease pathology. Proc. Natl. Acad. Sci. USA 91: 5710-5714.

7. Yan SD, Chen X, Schmidt AM, et al. (1994) Glycated tau protein in Alzheimer disease: a mechanism for induction of oxidant stress. Proc. Natl. Acad. Sci. USA 91: 7787-7791.

8. Sasaki N, Fukatsu R, Tsuzuki K, et al. (1998) Advanced glycation end products in Alzheimer's disease and other neurodegenerative diseases. Am. J. Pathol. 153: 1149-1155.

9. Castellani, R, Smith MA, Richey PJ, Petty G. (1996) Glycoxidation and oxidative stress in Parkinson disease and diffuse Lewy body disease. Brain Res. 737: 195-200.
10. Shibata N, Hirano A, Kato S, et al. (1999) Advanced glycation endproducts are deposited in neuronal hyaline inclusions: a study of familial amyotrophic lateral sclerosis with superoxide dismutase-1 mutation. Acta Neuropathol. 97: 240-246.

11. Chou SM, Wang HS, Taniguchi A, Bucala R. (1998) Advanced glycation end products in neurofilament conglomeration of motoneurons in familial and sporadic amyotrophic lateral sclerosis. Mol. Med. 4: 324-332.

12. Konishi Y, Hayase F, Kato H. (1994) Novel imidazolone compound by the advanced Maillard reaction of 3-deoxyglucosone and arginine residues in proteins. Biosci. Biotech. Biochem. 58: 1953-1955.

13. Hayase F, Konishi Y, Kato H. (1995) Identification of the modified structure of arginine residues in proteins with 3-deoxyglucosone, a Maillard reaction intermediate. Biosci. Biotech. Biochem. 59: 1407-1411.

14. Fu MX, Requena JR, Jenkins AJ, Lyons TJ, Baynes JW, Thorpe SR. (1996) The advanced glycation end product, $\mathrm{N}$-(carboxymethyl)lysine, is a product of both lipid peroxidation and glycoxidation reactions. J. Biol. Chem. 271: 99829986.

15. Wells-Knecht KK, Lyons TJ, McCance DR, Thorpe SR, Feather MS, Baynes JW. (1994) 3-Deoxyfructose concentrations are increased in human plasma and urine in diabetes. Diabetes 43: 1152-1156.

16. Nagaraj RH, Sady C. (1996) The presence of a glucose-derived Maillard reaction product in the human lens. FEBS Lett. 382: 234-238.

17. Al-Abed Y, Kapurniotu A, Bucala R. (1999) Advanced glycation end products; detection and reversal. Methods Enzymol. 309: 152-172.

18. Lal S, Szwergold BS, Taylor AH, et al. (1995) Metabolism of fructose-3-phosphate in the diabetic rat lens. Arch. Biochem. Biophys. 318: 191-199.

19. Dyer DG, Blackledge JA, Thorpe SR, Baynes JW. (1991) Formation of pentosidine during nonenzymatic browning of proteins by glucose. Identification of glucose and other carbohydrates as possible precursors of pentosidine in vivo. J. Biol. Chem. 266: 11654-11660.

20. Niwa T. (1999) 3-Deoxyglucosone: metabolism, analysis, biological activity, and clinical implication. J. Chromatogr. B 731: 23-36.

21. Niwa T, Katsuzaki T, Momoi T, et al. (1996) Modification of beta $2 \mathrm{~m}$ with advanced glycation end products as observed in dialysis-related amyloidosis by 3-DG. accumulating in uremic serum. Kidney Int. 49: 861-867.

22. Odani H, Shinzato T, Matsumoto Y, Usami J, Maeda K. (1999) Increase in three $\alpha, \beta$-dicarbonyl compound levels in human uremic plasma: specific in vivo determination of intermediates in advanced Maillard reaction. Biochem. Biophys. Res. Commun. 256: 89-93.

23. Khadem HE, Horton D, Meshreki MH, Nashed MA. (1971) New route for the synthesis of 3-deoxyaldos-2-uloses. Carbohyd. Res. 17: 183-192.

24. Makita Z, Vlassara H, Cerami A, Bucala R. (1992) Immunochemical detection of advanced glycosylation end products in vivo. J. Biol. Chem. 267: 5133-5138.

25. Takeuchi M, Makita Z, Yanagisawa K, Kameda Y, Koike T. (1999) Detection of noncarboxymethyllysine and carboxymethyllysine advanced glycation end products (AGE) in serum of diabetic patients. Mol. Med. 5: 393-405.

26. Takeuchi M, Makita Z, Bucala R, Suzuki T, Koike T, Kameda Y. (2000) Immunological evidence that non-carboxymethyllysine advanced glycation end-products are produced from short chain sugars and dicarbonyl compounds in vivo. Mol. Med. 6: 114-125.

27. Ikeda K, Higashi T, Sano H, et al. (1996) N-(carboxymethyl) lysine protein adduct is a major immunological epitope in proteins modified with advanced glycation end products of the Maillard reaction. Biochemistry 35: 8075-8083.

28. Ahmed MU, Frye EB, Degenhardt TP, Thorpe SR, Baynes JW. (1997) N-(Carboxyethyl)lysine, a product of the chemical 
modification of proteins by methyglyoxal, increases with age in human lens proteins. Biochem. J. 324: 565-570.

29. Takeuchi M, Bucala R, Suzuki T, et al. (2000) Neurotoxicity of advanced glycation end-products for cultured cortical neurons. J. Neuropathol. Exp. Neurol. 59: 1094-1 105.

30. Brinkmann-Frye E, Degenhardt TP, Thorpe SR, Baynes JW. (1998) Role of the Maillard reaction in aging of tissue proteins: advanced glycation end product-dependent increase in imidazolium cross-links in human lens proteins. J. Biol. Chem. 273: 18714-18719.

31. Degenhardt TP, Thorpe SR, Baynes JW. (1998) Chemical modification of proteins by methylglyoxal. Cell. Mol. Biol. 44: 1139-1145.

32. Tessier F, Obrenovich M, Monnier VM. (1999) Structure and mechanism of formation of human lens fluorophore LM-1: relationship to vesperlysine $\mathrm{A}$ and the advanced Maillard reaction in aging, diabetes, and cataractogenesis. J. Biol. Chem. 274: 20796-20804.
33. Chellan P, Nagaraj RH. (1999) Protein crosslinking by the Maillard reaction: dicarbonyl-derived imidazolium crosslinks in aging and diabetes. Arch. Biochem. Biophys. 368: 98-104.

34. Baynes JW, Thorpe SR. (1999) Role of oxidative stress in diabetic complications: a new perspective on an old paradigm. Diabetes 48: 1-9.

35. Uchida K. (2000) Role of reactive aldehyde in cardiovascular diseases. Free Rad. Biol. Med. 28: 1685-1696.

36. Baynes JW, Thorpe SR. (2000) Glycoxidation and lipoxidation in atherogenesis. Free Rad. Biol. Med. 28: 1708-1716.

37. Wells-Knecht KJ, Zyzak DV, Litchfield SR, Thorpe SR, Baynes JW. (1995) Mechanism of autoxidative glycosylation: identification of glyoxal and arabinose as intermediates in the autoxidative modification of proteins by glucose. Biochemistry 34: 3702-3709.

38. Wells-Knecht MC, Thorpe SR, Baynes JW. (1995) Pathways of formation of glycoxidative products during glycation of collagen. Biochemistry 34: 15134-15141. 